\title{
TREND REFORMASI PENDIDIKAN DI AUSTRALIA
}

\author{
Muhammad In'am Esha \\ Dosen pada program studi Bahasa Inggris UIN Malang
}

\begin{abstract}
Change is an important term in this era. Change is a phenomenon that able to seen in various aspects such as politic, economic, social, and education. Political reform or education reform that make a trend in the world, actually speak about change. This paper examines education reform in Australia. This study shows several aspect on that phenomenon. First, education reform in Australia influenced by spreading of neoliberalism trend in the world with a famous term: new public management paradigm. As member of OECD, Australia must develop and modernize its education as well as in New Zealand, England, Japan, and USA. Second, education reform needed for competing in globalization era. Relation of education with increasing human resources is an important factor that encourage education reform. Third, education reform in Australia include two aspect: managerial aspect and content of education (curriculum).
\end{abstract}

Keyword: Reform, Education, New Public Management.

\section{A. Pengantar}

Salah satu hal penting yang menandai akhir abad ke-20 adalah adanya kemajuan teknologi dan komunikasi sebagai berkah dari penemuan mutakhir manusia dalam bidang komputer dan teknologi jaringan (computer and web technology). Dua hal inilah yang ikut menandai terjadinya pergerakan yang luar biasa dalam kehidupan manusia. Dengan kecanggihan teknologi itu manusia saat ini memasuki satu era yang dikenal dengan era globalisasi.

Globalisasi yang telah merasuk dalam relung-relung kehidupan masyarakat modern telah mendorong perubahan-perubahan sosial yang dahsyat. Betapa tidak, tatanan-tatanan kehidupan yang dulu mengandalkan cara-cara konvensional mau tidak mau harus diubah dengan pemanfaatan teknologi komputasi dan jaringan. Konsekwensinya, 
Muhammad In'am Esha - Trend reformasi Pendidikan di Australia

manusia dipaksa untuk mengejar dan mengikuti perkembangan yang ada. Mereka harus melek teknologi komputer dan jaringan (computer and web litterate) jika ingin bersaing di tingkat global. Jika ti

dak, dapat dipastikan mereka akan tertinggal dengan percepatan perkembangan ilmu pengetahuan dan teknologi yang ada (Balasubramaniam, 2001:30).

Tidak hanya itu, dampak dari kemajuan ilmu pengetahuan dan teknologi telah memaksa manusia untuk melakukan efisiensi-efisiensi. Hal ini tidak lain karena dengan kemajuan teknologi pekerjaan-pekerjaan yang sifatnya padat karya dapat tergantikan oleh teknologi. Dalam konteks persaingan global adagium ekonomis, efektif, dan efisien menjadi hal yang tidak dapat disepelekan. Hal inilah yang pada gilirannya mendorong terjadinya reformasi di berbagai belahan dunia.

Reformasi administrasi yang dilaksanakan oleh berbagai negara menyangkut banyak segi baik politik, sosial, ekonomi, dan juga pendidikan. Administrasi pendidikan perlu dilakukan reformasi di antaranya berangkat dari pemikiran bahwa pendidikan merupakan salah satu soko guru yang menentukan tingkat kemajuan suatu bangsa. Terletak pada pendidikanlah nasib sebuah bangsa ditentukan. Seperti yang dikatakan oleh Tilaar (1994: 171) bahwa melalui pendidikanlah transfer ilmu pengetahuan dan teknologi dapat dilaksanakan. Melalui pendidikan juga, transfer nilai-nilai suatu bangsa dapat dilakukan dari satu generasi ke generasi. Lewat pendidikanlah dalam kenyataannya fungsi-fungsi antisipatoris-prepatoris dapat dijalankan, di samping tentunya fungsifungsi transfer of knowledges and values.

Oleh karenanya, dalam kondisi masyarakat global yang terus berubah pendidikan juga harus mengikuti perkembangan zaman. Pendidikan harus sesuai dengan semangat dan ruh zaman jika tidak ingin ditilap atau ditinggalkan. Administrasi pendidikan pun perlu dibenahi agar sesuai dengan kebutuhan dan perkembangan yang ada. Hal inilah yang mendorong pentingnya reformasi administrasi publik pendidikan dari waktu ke waktu.

Terkait dengan perbincangan di atas, tulisan ini akan mengajak pembaca untuk belajar tentang reformasi pendidikan yang telah dilakukan di Australia. Harapannya tentu kita akan mencoba untuk mengkaji reformasi macam apa yang telah dilakukan Australia terkait dengan pendidikannya. Dengan begitu, kita pun bisa mengambil pelajaran dari peristiwa tersebut. 
Muhammad In'am Esha - Trend reformasi Pendidikan di Australia

Untuk lebih memudahkan pembahasan, dalam tulisan ini akan dipaparkan hal-hal sebagai berikut: 1) New Public Management (NPM) dan Reformasi Administrasi Publik; 2) Reformasi Pendidikan di Australia. Dalam hal ini akan dibahas dua hal yaitu: Melacak Akar Reformasi Pendidikan di Australia dan Reformasi Pendidikan di Australia; 3) Refleksi atas fenomena reformasi pendidikan di Australia; dan 4) Penutup.

\section{B. New Public Management (NPM) dan Reformasi Administrasi Publik}

Apa yang akan dipaparkan dalam sub pembahasan ini merupakan kerangka teoretik yang akan dijadikan perspekif dalam membaca realitas reformasi administrasi pendidikan yang terjadi di Australia. Seperti yang dijelaskan oleh Nolan (2001) bahwa reformasi pendidikan di Australia sangat lekat dengan paradigma yang dikenal dengan New Public Management (NPM). Hal inilah yang kemudian saya katakan bahwa reformasi pendidikan yang terjadi di Australia sebagai New Public Management driven reform. Namun, ada baiknya sebelum kita membahas lebih lanjut tentang NPM kita mendedar dahulu apa yang dimaksud dengan reformasi administrasi itu.

\section{Reformasi Administrasi}

Pollitt \& Bouckaert (2000: 8) mengatakan bahwa 'public management reform consist of deliberate changes to the structures and processes of public sector organizations with the objectives of getting them (in some sense) to run better.' Meskipun, dalam bukunya tersebut Pollit dan Bouckaert tidak menyebutkan reformasi administrasi publik tetapi reformasi manajemen publik, tetapi sebenarnya kita bisa mengambil ruh dari paparan yang diberikan tersebut terkait dengan reformasi. Menurut mereka, reformasi merupakan perubahan baik yang berkenaan dengan struktur ataupun proses dalam organisasi publik agar tujuan-tujuannya dapat dilaksanakan atau dicapai secara lebih baik.

Dalam konteks ini, tidak salah apa yang dinyatakan oleh Zauhar (2007: ), misalnya, dalam tulisannya bahwa memang dalam banyak kasus reformasi memberikan harapan besar dari banyak masyarakat. Reformasi kalau kita menilik dari apa yang dideskripsikan oleh Pollit dan Bouckaert di atas memang istilah itu seolah menjadi opium yang sering menjadi tempat pelarian sosial dari berbagai permasalah yang dihadapi. Walaupun dalam kenyataannya, keberhasilan reformasi sangat tergantung pada 
Muhammad In'am Esha - Trend reformasi Pendidikan di Australia

pelaku, strategi, dan kondisi lingkungan yang ada. Tidak jarang, ketika telah digulirkan reformasi bukan kebaikan yang muncul, malah sebaliknya.

Caiden (1968: 69) dalam tulisannya tentang Prospects for Administrative Reform in Israel mendefinisikan reformasi administrasi sebagai 'the artificial inducement of administrative transformation againts resistance'. Definisi Caiden ini mengandung beberapa implikasi:(1) Reformasi administrasi merupakan kegiatan yang dibuat oleh manusia (manmade), tidak bersifat eksidental, otomatis maupun alamiah; (2) Reformasi administrasi merupakan suatu proses; (3) Resistensi beriringan dengan proses reformasi administrasi.

Dengan demikian, reformasi administrasi mengandung makna bahwa ia dilakukan dengan sadar dan terencana oleh manusia. Ia adalah sebuah proses untuk mentransformasikan organisasi ke arah yang lebih baik. Namun, kelebihan dari apa yang dideskripsikan Caiden ini adalah bahwa ia sudah menyiratkan bahwa perubahan ke arah yang lebih baik itu bukanlah tanpa tantangan. Reformasi pada galib-nya senantiasa akan dihadapkan pada sejumlah resistensi-resistensi. Dengan kesadaran semacam ini kiranya diharapkan pada aktor yang terlibat dalam reformasi tersebut akan dapat menyiapkan strategi-strategi yang tepat untuk mengantisipasi kendala-kendala yang dihadapi.

Caiden membedakan antara administrative reform dan administrative change. Perubahan administrasi bermakna sebagai respons keorganisasian yang sifatnya otomatis terhadap fluktuasi atau perubahan kondisi (Caiden, 1968: 57-58). Lebih lanjut dikatakan bahwa munculnya kebutuhan akan reformasi administrasi sebagai akibat dari adanya perubahan administrasi. Tidak berfungsinya perubahan administrasi yang alamiah ini menyebabkan diperlukannya reformasi administrasi (Caiden, 1968: 65).

Caiden menyebut tujuan, isi dan ruang lingkup reformasi administrasi adalah sebagai berikut: (1). Tujuan yang ingin dicapai seorang pembaru administrasi yang notabene juga merupakan tujuan reformasi administrasi untuk menyempurnakan kinerja individu, kelompok dan institusi. Di samping itu, reformasi administrasi bertujuan juga memberi saran tentang bagaimana caranya agar individu, kelompok dan institusi, dapat mencapai tujuan lebih efektif, ekonomis, dan lebih cepat. Dengan rumusan lain Caiden menyebut tujuan reformasi administrasi adalah untuk ... improve the administrative performance of individual, groups, and institutions and to advise them how they can achieve their operating goals more effectively, more economically, and more quickly (Caiden, 1968: 12). 
Jika dianalisis selanjutnya, tujuan reformasi administrasi Caiden adalah menyempurnakan atau meningkatkan performance. Konsep inilah yang Caiden sebut administrative health, yaitu suatu situasi di mana administrasi tidak hanya mampu memenuhi segala macam tuntutan yang dibebankan kepadanya, namun juga administrasi yang di dalamnya tak dijumpai gelagat yang tak baik (Caiden, 1968: 25). (2) Isi dan ruang lingkup reformasi administrasi mencakup kinerja baik kinerja individu, kelompok, dan institusi. Ini berarti di samping aspek perilaku, juga aspek kelembagaan yang tercakup di dalam reformasi administrasi. Sehat tidaknya administrasi dapat dilihat dari tiga perspektif yang berbeda, yaitu:(1) Ideal optimum, yakni derajat pencapaian kesempurnaan administrasi; (2) Practical optimum, yakni pencapaian derajat tertinggi dari suatu kinerja dalam kondisi tertentu; (3) Satisficing optimum, yakni pencapaian derajat kinerja yang memuaskan.

Sedangkan peningkatan kinerja individu dapat dilihat dari keterampilannya, kecakapan, praktisnya, kompetensinya, pengetahuan dan informasinya, keluasan pengalamannya, sikap dan perilakunya, kebajikannya, kreativitasnya, moralitasnya dan lain-lain. Kinerja kelompok dilihat dari aspek kerja samanya, keutuhannya, disiplinnya, loyalitasnya, dan lain-lain. Sedangkan kinerja institusi dapat dilihat dari hubungannya dengan institusi lain, fleksibilitasnya, adaptabilitasnya, pemecahan konflik dan lain-lain.

Reformasi administrasi menurut Dror (1971: 19), secara tegas mengesampingkan perubahan organisasi dan prosedur administrasi yang minor dan berkonsentrasi pada perubahan-perubahan yang utama atau dasar saja, sehingga reformasi administrasi itu akan efektif apabila juga didesain dengan tepat, yakni dengan mempertimbangkan dan melibatkan lingkungan di mana reformasi itu dilaksanakan. Reformasi administrasi dipandang sebagai bagian dari reformasi masyarakat (Caiden, 1968: 4), sebab birokrasi dan organisasi pemerintah merupakan bagian dari dan berkaitan erat dengan sistem politik, sosial, ekonomi, dan sebagainya.

Setelah kita membahas sekilas tentang reformasi administrasi, berikut akan dijelaskan beberapa hal yang terkait dengan New Publik Management (NPM). Dalam konteks ini, kita tidak akan menjelaskan tentang berbagai masalah yang terkait dengan NPM ini, tetapi pembahasan akan lebih difokuskan pada karakteristik NPM, model dalam NMP, dan strategi perubahan yang dapat ditempuh. 
Muhammad In'am Esha - Trend reformasi Pendidikan di Australia

\section{New Public Management (NPM)}

Seperti yang dijelaskan Hughes dalam bukunya yang berjudul Public Management and Administration (1994) bahwa pada awal 1990an telah terjadi suatu transformasi dalam konteks administrasi. Perubahan tersebut berbentuk perubahan administrasi publik yang kaku, hirarkhis, dan birokratis menuju ke bentuk manajemen publik yang fleksibel dan berbasis pasar. Inilah yang kemudian kita kenal dengan istilah public management dan new public management.

Pola administrasi lama yang lebih menekankan pada model administrasi Weberian dianggap telah gagal dalam memenuhi kebutuhan publik. Blau dan Meyer (1987), misalnya, melihat birokrasi memiliki sisi gelap yaitu adanya kekakuan (inflexibility), kemandegan struktural (structural static), tata cara yang berlebihan (ritualism), penyimpangan sasaran (pervesion goals), sifat yang tidak pribadi (impersonality), dan pengabaian (alienation) serta otomatis (automatism) dan menutup diri terhadap perbedaan pendapat (constrain of dissent). Oleh karenanya, organisasi model ini dipandang tidak cocok dengan perkembangan zaman yang ditandai dengan perubahan-perubahan yang sedemikian cepat.

Seperti diketahui bahwa NPM pada prinsipnya merupakan upaya untuk mengusung nilai-nilai pasar ke dalam ranah publik. Namun demikian, terdapat perbedaan fundamental di dalamnya. Bagi mereka yang melihat management sciences itu bersifat generik, maka ini berarti bahwa prinsip, fungsi dan proses manajemen di sektor publik sama dengan di sektor bisnis. Sebaliknya bagi mereka yang melihat 'public administration' itu berbeda dengan administrasi bisnis karena mereka memiliki sistem nilai, ideologi, landasan intelektual berbeda. Administrasi bisnis merupakan produk dari ideologi kapitalis yang orientasinya profit, sedangkan administrasi publik mewarisi ideologi konstitusionalistik seperti kesejahteraan sosial, kesetaraan akses dan perlakukan (Islamy, 2003: 57).

Secara konsepsual NPM memiliki lima hal yaitu: The adoption of private sector management practices in the public sector, An emphasis on efficiency, A movement away from input controls, rules and procedures toward output measurement and performance targets, A preference for private ownership, contestable provision, and contracting out of public services, dan The devolution of management control with improved reporting and monitoring mechanism.

Hood (1991) sebagaimana dikutip Nolan (2001: xix-xxx) menyajikan tujuh ciri dari NPM, yaitu: (a) pelaksanaan tugas diserahkan pada manajer 
profesional, (b) adanya standar dan ukuran kerja yang jelas, (c) penekanan yang lebih pada kontrol hasil, (d) pembagian tugas ke dalam unit-unit yang ada di bawahnya, (e) ditumbuhkan persaingan di tubuh sektor publik, (f) lebih menekankan diterapkannya gaya manajemen sektor privat, dan (g) lebih ditekankan pada kedisiplinan yang tinggi dan tidak boros.

Di samping itu, menurut Nolan, NPM memiliki empat model, yaitu: (a) the efficiency drive. NPM biasanya mengambil model kearah efisiensi; (b) Downsizing and decentralization. Model yang lebih menekankan pada pemangkasan dan desentralisasi; (c) in search of excellence. Model yang menekankan pada pencarian keunggulan-keunggulan; (d) Public Service orientation. Model yang berorientasi pada pelayanan publik. Keempat model ini dalam kenyataannya bukanlah berdiri sendiri-diri, tetapi lebih merupakan satu hal yang saling terkait antara satu dengan lainnya.

Untuk mewujudkan reformasi administrasi publik, terdapat strategi perubahan yang dapat ditempuh. Dalam bukunya tersebut Nolan (2001) menjelaskan bahwa terdapat 4 (empat) tipe yang bisa dilakukan dalam melakukan perubahan, yaitu:

- Tipe 1: Evolusi Partisipatori (Participatory Evolution)

Dalam tipe ini, strategi perubahan dilakukan secara evolusi atau bertahap (incremental adjustment). Dalam tipe ini, perubahan dicapai dengan menekankan pendekatan yang bersifat konsultatif dan kolaboratif antar komponen-komponen yang dan dengan mempertimbangkan realitas kondisi yang ada.

- Tipe 2: Transformasi Karismatik (Charismatic Transformation) Tipe ini dilakukan untuk perubahan yang dramatis dalam skala yang luas. Dalam model ini tetap menggunakan pendekatan yang mengedepankan aspek-aspek konsultatif dan kolaboratif. Largescale discontinuous change, achieved by collaborative means

- Tipe 3: Evolusi yang Kuat (Forced Evolution)

Tipe ini dilakukan dalam konteks perubahan yang bertahap (incremental adjustment) tetapi dengan pendekatan yang besifat directive dan paksaan, koersif.

- Tipe 4: Transformasi Diktatorial (Dictatorial Transformation) Tipe ini dilakukan dalam bentuk perubahan dalam skala yang luas dan bersifat discontinuous dengan pendekatan yang bersifat direktif dan koersif (directive and coersive approach).

Dalam konteks reformasi administrasi, kita bisa menempuhnya dalam model atau tipe seperti yang dijelaskan oleh Nolan di atas. Tetapi, 
kalau kita sandingkan dengan apa yang dijelaskan oleh Farazman dalam bukunya Administrative reform in Development Nations (2002: 3-5), maka sebenarnya kita akan bisa memahami lebih lanjut tentang model dalam reformasi administrasi. Ia mengatakan bahwa setidaknya ada tiga model dalam reformasi administrasi. Pertama, model top-down. Dengan model ini Farazman ingin menjelaskan bahwa reformasi administrasi publik dapat dilakukan dan diprakarsai oleh para "atasan" seperti elit politik, sosok yang kuat dan berpengaruh. Kedua, Model Bottom-up atau model yang dikondisikan oleh lingkungan. Dengan model ini, Farazman mengatakan bahwa reformasi bisa terjadi karena dipengaruhi oleh kondisi yang ada baik itu sosial, politik, ekonomi, maupun budaya. Tuntutan dari luar inilah yang kemudian mempengaruhi dalam reformasi administrasi publik. Ketiga, Model institusional. Berbeda dengan dua model di atas, pendekatan ini lebih menitikberatkan pada pentingnya perubahan nilai-nilai kolektif, budaya organisasi, dan strukturnya yang diharapkan akan berpengaruh pada administrasi publik agar lebih bersifat adaptif dan dinamis.

Tipe-tipe Strategi Perubahan menurut Nolan (2001)

\begin{tabular}{|c|c|c|c|c|}
\hline $\begin{array}{l}\text { Style of } \\
\text { Management }\end{array}$ & $\begin{array}{l}\text { Fine } \\
\text { Tuning }\end{array}$ & $\begin{array}{l}\text { Incremental } \\
\text { adjustment }\end{array}$ & $\begin{array}{l}\text { Modular } \\
\text { Transformatio }\end{array}$ & $\begin{array}{l}\text { Corporate } \\
\text { transformation }\end{array}$ \\
\hline Collaborative & & & & \\
\hline & \multicolumn{2}{|c|}{$\begin{array}{c}\text { Type } 1 \\
\text { Participative } \\
\text { Evolution }\end{array}$} & \multicolumn{2}{|c|}{$\begin{array}{c}\text { Type } 1 \\
\text { Charismatic } \\
\text { Transformation }\end{array}$} \\
\hline Directive & \multirow{2}{*}{\multicolumn{2}{|c|}{$\begin{array}{c}\text { Type } 1 \\
\text { Forced } \\
\text { Evolution }\end{array}$}} & \multicolumn{2}{|c|}{$\begin{array}{c}\text { Type } 1 \\
\text { Dictatorial } \\
\text { Transformation }\end{array}$} \\
\hline Coercive & & & & \\
\hline
\end{tabular}


Muhammad In'am Esha - Trend reformasi Pendidikan di Australia

\section{Reformasi Pendidikan di Australia \\ 1. Melacak Akar Reformasi}

Reformasi pendidikan yang terjadi di Australia, tidak dapat dilepaskan dari kondisi makro yang terjadi di negara-negara lain seperti di Inggris, Amerika, New Zealand. Reformasi yang dilakukan di beberapa negara di dunia pada saat itu tidak dapat dilepaskan dari kondisi masyarakat yang sedang dilanda berbagai problem seperti rendahnya kualitas pendidikan sehingga daya serap di pasar kerja merosot yang berdampak pada kondisi ekonomi negara pada saat itu.

Amerika, misalnya, melakukan reformasi pendidikan terkait dengan laporan A Nation at Risk 1983, yang memaparkan bahwa penurunan kualitas ekonomi terkait dengan rendahnya kualitas pendidikan dan disarankan untuk melakukan perbaikan sebagai salah satu langkah dalam revitalisasi ekonomi Amerika. National Commission on Excellence in Education menjelaskan bahwa seiring dengan perkembangan negara menjadi lebih aktif untuk mereformasi pendidikan dengan membuat standar pendidikan: meningkatkan kredit setiap mata pelajaran yang dibutuhkan bagi para lulusan, memunculkan standar bagi persiapan guru, sertifikasi guru, menetapkan tingkat gaji guru, dikembangkannya framework kurikulum negara, dan diadakannya ujian siswa secara nasional.

Pemerintah Amerika akhirnya melakukan langkah-langkah penataan manajemen kelembagaan pendidikan yang mengkombinasikan sentralisasi dan desentralisasi sejalan dengan trend privatisasi seperti yang terjadi di Inggris. Legislator dan dewan pendidikan negara menetapkan standar-standar bagi dewan pendidikan lokal dan dewan sekolah. Pemerintah juga menetapkan Site-based management. Pemerintah, dalam rangka memberikan peningkatan jumlah pilihan sekolah dan menumbuhkan iklim kompetisi memberikan ijin berdirinya sekolahsekolah baru. Bahkan, juga memberikan hadiah-hadiah dan kredit-kredit pembayaran pajak untuk sekolah swasta (Lee, 2001: 6).

Demikian halnya yang terjadi di Australia, reformasi pendidikan tidak dapat dilepaskan dari resonansi reformasi yang terjadi di negaranegara tersebut. Namun demikian, secara internal terdapat beberapa aspek yang berpengaruh atau menjadi pendorong dilaksanakannya reformadi pendidikan di Australia. Seperti yang dijelaskan oleh Barcan (2001: 85-92), bahwa setidaknya terdapat empat faktor penting yang mendorong reformasi pendidikan di Australia, yaitu: 
Muhammad In'am Esha - Trend reformasi Pendidikan di Australia

Pertama, terjadinya krisis dari negara kesejahteraan dan munculnya ekonomi neoliberalisme yang lebih menekankan pada nilai-nilai kompetisi, pasar bebas, dan meminimalkan intervensi negara.

Kedua, adanya kecenderungan pemerintah untuk melakukan efisiensi dengan mengurangi biaya belanja negara terhadap birokrasi pendidikan dan pelayanan pendidikan.

Ketiga, kecenderungan masyarakat Australia untuk mencari pendidikan yang kurikulumnya mengorientasikan pendidikannya pada kebutuhan pasar kerja atau pendidikan yang bersifat vokasional. Di samping itu, masyarakat Australia mulai menuntut kualitas pendidikan yang tinggi.

Keempat, adanya ketidakpuasan yang dirasakan oleh para orang tua di Australia terhadap pelayanan yang diberikan oleh sekolah-sekolah pemerintah.

\section{Realitas Reformasi Pendidikan di Australia}

Kondisi yang terjadi di Australia di atas, mendorong dilaksanakan reformasi. Berikut dijelaskan beberapa fakta-fakta reformasi pendidikan negeri di Australia tersebut seperti yang nampak dalam reformasi pendidikan di beberapa negara bagian.

Negara bagian New South Wales (NSW). Reformasi pendidikan yang terjadi di negara bagian NSW termanifestasikan dalam beberapa kebijakan berikut:

Pemerintah negara bagian melaksanakan kebijakan pergeseran administrasi dari pemerintah pusat kepada sekolah masing-masing dengan mengenalkan atau membentuk komite sekolah (school council). Komite sekolah yang anggotanya diambilkan dari para orang tua murid dan tokoh masyarakat mempunyai kewenangan untuk mengukur 'biaya belanja sekolahnya'. Dengan hal ini diharapkan sekolah-sekolah akan mampu untuk memikirkan sumber-sumber pendanaan lain di luar negara. Tercatat menjelang 1992, 45\% sekolah-sekolah negeri telah mempunyai komite sekolah.

Seperti yang terjadi di negara-negara lain, kebijakan ini diambil dalam rangka memberikan keleluasaan kepada masing-masing sekolah untuk mengelola pendidikannya dan mengurangi ketergantungannya kepada pusat. Hal ini juga nantinya berimplikasi pada perampingan organisasi di tingkat pusat karena berbagai kepentingan banyak yang didelegasikan ke dewan sekolah. Seperti yang dijelaskan oleh Barcan, di 
Muhammad In'am Esha - Trend reformasi Pendidikan di Australia

NSW dilaksanakan perampingan dan juga restrukturisasi. Departemen pendidikan diubah menjadi departemen pendidikan sekolah di mana pimpinan kantor berkedudukan sebagai eksekutif pusat.

Reformasi pendidikan yang dilaksanakan di Australia barat dikenal dengan by product of public service reform. Di negara bagian ini reformasi dilakukan di antaranya dengan melakukan perampingan kantor-kantor pusat, devolusi pelayanan administrasi, dan upaya peningkatan akuntabilitas. Rekomendasi ini merupakan hasil survei dari Komite Review Fungsional (A Functional Review Committee) yang melakukan survei terhadap departemen-departemen pemerintah.

Restrukturisasi ditingkat departemen dilaksanakan, misalnya, dengan merampingkan struktur kementerian pendidikan. Lebih dari 1000 posisi di kantor pusat dibubarkan. Penataan kurikulum dengan mengenalkan kurikulum tingkat satuan dan juga berbaikan kondisi kerja guru dan gajinya. Di negara bagian ini tidak membentuk komite sekolah, tetapi mengenalkan Kelompok Pembuat Kebijakan Sekolah (A School Decision Making Groups).

Di negara bagian Queensland, reformasi dilaksanakan dalam bentuk desentralisasi yaitu dengan secara bertahap mengalihkan manajemen kepada sekolah. Pada 1991, staf kantor pusat dikurangi, 11 wilayah administrasi didirikan, 47 pusat-pusat pendukung sekolah didirikan, dan 20 dewan penasehat sekolah diujicobakan.

Di negara bagian Australia Selatan, seperti di Victoria dan Wilayah Ibukota Australia, reformasi dilaksanakan dalam bentuk devolusi, pendirian komite sekolah, perbaikan kurikulum, dan desentralisasi manajerial. Hal ini sebagaimana juga dilakukan di Wilayah Utara. Namun demikian, di wilayah ini yang lebih menonjol adalah perampingan staf adminstrasi dengan jalan mentransfer tugas mereka menjadi personilpersonal di sekolah-sekolah. Di samping itu, dilakukan amandemen atas Undang-undang Pendidikan yang memberikan kelonggaran kepada komite sekolah untuk menerima atau menolak manajemen pengelolaan keuangannya.

\section{Refleksi: Trend Reformasi Pendidikan}

Mencermati realitas reformasi pendidikan negeri di Australia, maka sangat nampak betapa semangat NPM menjadi trendnya. NPM pada hakikatnya disemangati oleh sebuah ideologi kaum manajerial atau biasa dikenal dengan manajerialisme atau dalam bahasa Fusarelli dan Johnson 
Muhammad In'am Esha - Trend reformasi Pendidikan di Australia

(2004: 118) disebut sebagai neo-corporatist ideology. Dalam konteks manajerialisme, konsen utamanya terletak pada efisiensi dan kontrol administratif. Realitas ini muncul seiring dengan globalisasi yang tengah melanda dunia (Beckmann \& Cooper, 2004: 1).

Reformasi di Australia seperti yang telah dilakukan oleh negaranegara bagiannya, setidaknya menampakkan kecenderungan sebagai berikut:

Pertama, reformasi dalam konteks manajemen. Reformasi macam ini misalnya termanifestasikan dalam model perampingan (downsizing) dan desentralisasi manajerial dan tentunya juga peningkatan akuntabilitas. Meskipun, yang terakhir ini kurang mendapatkan porsi yang cukup dalam penjelasan Barcan, tetapi jelas bahwa akuntabilitas tidak dapat dinafikkan. Mengapa? Seperti yang dipaparkan ketika kita membahas persoalan akar terjadinya reformasi pendidikan dijelaskan bahwa keinginan orang tua agar dilaksanakan perubahan kurikulum yang sejalan dengan pasar kerja, maka itu merupakan salah satu bentuk akuntabilitas pendidikan (Nolan, Op.Cit.: 92).

Seperti diketahui bahwa dalam ranah akuntabilitas publik pendidikan dikenal dua model akuntabilitas yaitu akuntabilitas vertikal dan akuntabilitas horizontal (Tillaar, 2002: 26). Akuntabilitas horizontal dimaksudkan bahwa penyelenggaraan pendidikan haruslah memiliki relevansi dengan kebutuhan masyarakat yang menjadi stakeholder yang pertama dan utama dari proses pendidikan. Hal ini berarti proses pendidikan, tujuan pendidikan, sarana pendidikan, dan termasuk juga mutu pendidikan haruslah diarahkan sesuai dengan kepentingan dan kebutuhan masyarakat. Akuntabilitas horizontal pendidikan, dengan demikian, berarti pendidikan haruslah menjawab kebutuhan masyarakat yang memilikinya. Sedangkan akuntabilitas vertikal dimaksudkan bahwa sebagai suatu bangsa, pendidikan nasional memerlukan suatu sistem yang mengikat. Akuntabilitas vertikal menunjukkan suatu keinginan masyarakat untuk membangun satu bangsa dan satu kebudayaan. Rasa persatuan dari seluruh bangsa mewajibkan setiap orang untuk hidup bersama sebagai satu bangsa di dalam negara. Untuk mencapai tujuan tersebut pendidikan haruslah memiliki akuntabilitas vertikal yaitu keinginan untuk diatur oleh aturan yang disepakati bersama. Pemerintah pusat memiliki kewenangan-kewenangan dalam mengatur penyelenggaraan pendidikan nasional melalui standar-standar yang disepakati bersama seperti kurikulum nasional, sistem akreditasi dan evaluasi, sistem pemerataan pendidikan, dan kualita s pendidikan.

Kedua, reformasi yang berkenaan dengan konsen pendidikan itu sendiri seperti dalam bentuk reformasi kurikulum dan juga peningkatan 
kualitas pelayanan pembelajaran bagi siswa. Reformasi kurikulum dilakukan misalnya dengan memperkenalkan kurikum tingkat satuan pendidikan (the unit curriculum). Di samping itu untuk meningkatkan pendidikan dilakukan dengan meningkatkan standar pendidikan dan juga meningkatkan relevansi pendidikan dengan dunia kerja melalui pengenalan pendidikan vokasional (Nolan, 2001: 91).

Mengacu pada karakteristik yang dijelaskan Hood (1991: 4-5) seperti yang dikutip Nolan, sebenarnya reformasi yang dilakukan di Australia telah memenuhi beberapa karakteristik tersebut. Berikut tabel reformasi pendidikan negeri di Australia dengan mengacu pada karakteristik yang diberikan oleh Hood.

Tabel 1. Trend NPM dalam Manifestasi Reformasi Pendidikan Negeri di Australia

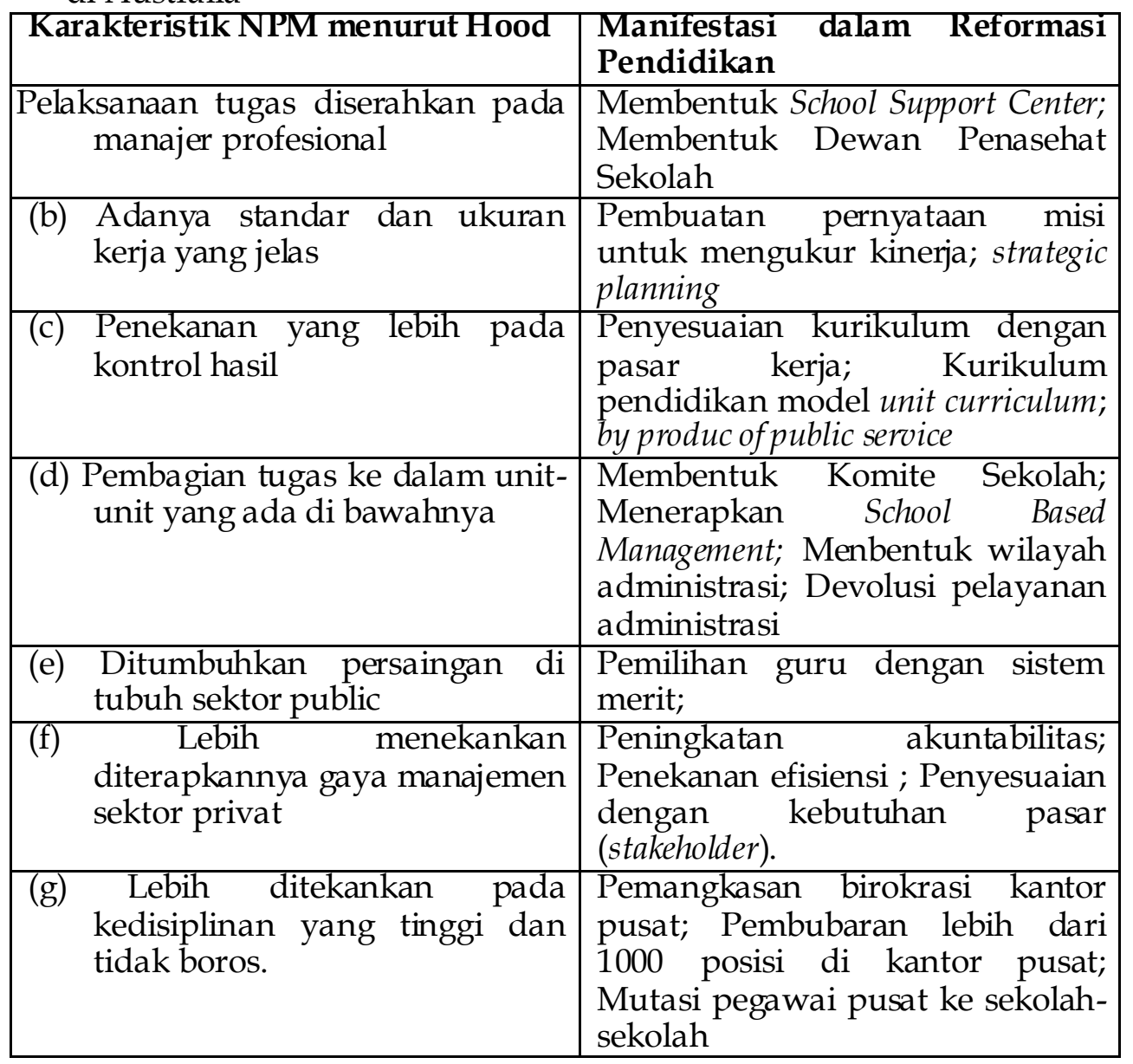


Muhammad In'am Esha - Trend reformasi Pendidikan di Australia

\section{E. Penutup}

Dari uraian di atas setidaknya dapat dicermati bahwa reformasi pendidikan negeri di Australia lebih banyak memperlihatkan spirit New Public Management (NPM). Hal itu dapat terlihat dengan semangat managerialisme yang diusung dalam aktivitas reformasi tersebut.

Sebagai penutup tulisan ini saya tertarik dengan apa yang disampaikan oleh Giddens. Ia mengatakan: Change is Risky, but No Change is Bigger Risk. Reformasi kiranya memang beresiko, tetapi tidak melakukan reformasi tentu akan memiliki resiko yang lebih besar. Terlebih, dalam kondisi zaman yang terus berubah dan berubah. Sebuah dunia yang selalu ber-panta rei, demikian kata filsuf Heraklitos.

\section{DAFTAR PUSTAKA}

Balasubramaniam, Arum. 2001. "Globalizing Medium, Multicultural Massage and Paradigm Generating Mode of Inquiry" dalam Yuen, Ng Chee dan Charla Griffy-Brown. 2001. Trends and Issues in East Asia 2001, Penerbit: IDRI.

Barcan, Alan. 2001. "The Reform of State Education in Australia" dalam Brendan C. Nolan, 2001. Public Sector Reform. New York: Palgrave.

Beckmann, Andre \& Charlie Cooper. 2004. "Globalisation, The New Managerialism and Education. dalam Journal of Critical Education Policy Studies Volume 2 Number 2 (September).

Blau, Peter M \& Meyer, Marshal W.. 1987. Birokrasi dalam Masyarakat Modern. Jakarta: UI Press.

Caiden, Gerald. 1968. Prospects for Administrative Reform in Israel. Public Administration Paper

Dror, Y. 1971. Strategies for Administrative Reform, Netherland: The Hague.

Farazman, Ali. 2002. Administrative Reform in Developing Nations. London: Praeger.

Fusarelli, Lance D. \& Bonnie Johnson. 2004. “Educational Governance and New Public Management" dalam Public Administration and Management: An Interactive Journal, 9 (2). 
Muhammad In'am Esha - Trend reformasi Pendidikan di Australia

Islamy. M. Irfan. 2003. 2003. Dasar-dasar Administrasi Publik dan Manajemen Publik. Malang: FIA UB.

Lee, Jaekyung, "School Reform Initiatives as Balancing Acts: Policy Variation and Educational Convergence among Japan, Korea, England and the United States" dalam Educational Policy Analysis Archive, Vol 9 Number 13, 24 April 2001.

Nolan, Brendan C., 2001. Public Sector Reform. New York: Palgrave.

Pollitt, Christopher \& Geert Bouckaert, 2000. Public Management Reform. Oxford: Oxford University Press.

Tilaar HAR. 1994. Manajemen Pendidikan Nasional. Bandung. Remaja Rosdakarya.

Tilaar, HAR. 2002. Membenahi Pendidikan Nasional. Jakarta: Rineka Cipta

Zauhar, Susilo. 2007. “Administrasi Publik Deliberatif dalam Masyarakat Nekrofilia" dalam Jurnal Administrasi Publik Vol. 9 No. 1. 